\title{
Autoimmunity and molecular mimicry in tropical spastic paraparesis/human T-lymphotropic virus-associated myelopathy
}

F. García-Vallejo ${ }^{1}$,

M.C. Domínguez ${ }^{1}$ and O. Tamayo ${ }^{2}$

\author{
${ }^{1}$ Laboratorio de Biología Molecular y Patogénesis, \\ Departamento de Ciencias Fisiológicas, Facultad de Ciencias da Saude, \\ Universidad del Valle, Cali, Colombia \\ ${ }^{2}$ Facultad de Medicina, Universidad Santiago de Cali, Cali, Colombia
}

Correspondence

F. García-Vallejo

Laboratorio de Biología Molecular

y Patogénesis

Departamento de Ciencias Fisiológicas

Facultad de Ciencias da Saude

Universidad del Valle, Cali

Colombia

E-mail: fegarva@telesat.com.co

Research supported in part by the Colombian government agency Colciencias (No. 1106-04-13063) and Universidad del Valle,

Cali, Colombia.

Received May 8, 2003

Accepted August 17, 2004

\begin{abstract}
Viruses share antigenic sites with normal host cell components, a phenomenon known as molecular mimicry. It has long been suggested that viral infections might trigger an autoimmune response by several mechanisms including molecular mimicry. More than 600 antiviral monoclonal antibodies generated against 11 different viruses have been reported to react with $3.5 \%$ of cells specific for uninfected mouse organs. The main pathological feature of tropical spastic paraparesis/ human T-lymphotropic virus type I (HTLV-I)-associated myelopathy (TSP/HAM) is a chronic inflammation of the spinal cord characterized by perivascular cuffing of mononuclear cells accompanied by parenchymal lymphocytic infiltration. We detected the presence of autoantibodies against a 98 - to $100-\mathrm{kDa}$ protein of in vitro cultured human astrocytes and a 33- to 35-kDa protein from normal human brain in the serum of HTLV-I-seropositive individuals. The two cell proteins exhibited molecular mimicry with HTLV-I gag and tax proteins in TSP/HAM patients, respectively. Furthermore, the location of 33- to $35-\mathrm{kDa}$ protein cross-reaction correlated with the anatomical spinal cord areas (in the rat model) in which axonal damage has been reported in several cases of TSP/HAM patients. Our experimental evidence strongly suggests that the demyelinating process occurring in TSP/ HAM may be mediated by molecular mimicry between domains of some viral proteins and normal cellular targets of the spinal cord sections involved in the neurodegeneration.
\end{abstract}

\section{Introduction}

Viruses that share antigenic sites with normal host cell components are part of a phenomenon known as molecular mimicry (1). It has long been suggested that viral infections might trigger an autoimmune response by several mechanisms including
Key words

- HTLV-I

- TSP/HAM

- Retrovirus

- Molecular mimicry 
leukemia virus type I (HTLV-I) after a long incubation period. TSP/HAM is characterized by chronic progressive paraparesis with sphincter disturbances, no or mild sensory loss, absence of spinal cord compression, and seropositivity for HTLV-I antibodies. The pathogenesis of this entity, reviewed by Casseb and Penalva-de-Oliveira (6), is not completely clear and involves a multivariable phenomenon of activation of the immunological system against the presence of HTLV-I antigens, leading to an inflammatory process with axomyelinic degeneration, mainly in the thoracic spinal cord (7).

The possible mechanisms by which HTLV-I infection contributes to the pathogenesis of TSP/HAM are unknown. HTLVI proviral DNA has been detected only in the nucleus of lymphocytes that infiltrated the spinal cord $(7,8)$. However, no proviral DNA was amplified in any neuronal cells, including neurons and glial cells $(9,10)$. This indicates that the axomyelinic degeneration of the spinal cord by HTLV-I is unlikely to be the result of viral infection of oligodendrocytes or of neuronal cells. These findings suggest an autoimmune mechanism in TSP/ HAM and that this neuronal process is probably associated with an activated cell- and antibody-mediated immune response in the patients.

Astrocytes are cells of the central nervous system (CNS) distinguished by their large star-shaped cell bodies and many radiating processes. Most of these processes form terminal expansions that surround the surface of blood vessels (11). Previous studies have shown that astrocytes secrete inflammatory cytokines after transient contact with T cells persistently infected with HTLV-I (12). These in vitro-activated astrocytes may prolong and amplify the pathological effects produced by invading $T$ cells, demonstrating the crucial role of astrocytes in brain homeostasis (13).

An important notion when considering the effect of viruses on the CNS is that certain impairments occurring in actually infected cells may be perpetuated via indirect effects of viruses on neural cells. Such impairment may persist and propagate via the secretion of soluble factors such as cytokines, chemokines, or metalloproteinases (14), and eventually alter the cell homeostasis. In the case of TSP/HAM this view is consistent with i) the presence in the lesions of cells expressing the viral product tax $(8,15)$, which is known to transactivate many cellular genes including several inflammatory molecules (16); ii) the expression of inflammatory cytokines in infiltrated $\mathrm{T}$ cells and astrocytes, and iii) the expression pattern of metalloproteinases and their inhibitors (17).

Viruses share antigenic sites with normal host cell components, a phenomenon known as molecular mimicry. It has long been suggested that viral infections might trigger an autoimmune response by several mechanisms including molecular mimicry $(4,13)$. In the present study, we performed some experiments in order to document the existence of molecular mimicry of monoclonal antibodies and sera of TSP/HAM patients against several proteins of HTLV-I with proteins and subcellular structures of nonHTLV-I/HIV-1-infected primary cultured human astrocytes and other normal components of the CNS.

\section{Patients and Methods}

\section{Characteristics of the sample}

We studied 47 serum samples from adult HTLV-I-seropositive persons belonging to different Colombian villages along the $\mathrm{Pa}$ cific coast, inland of the Southwest and Northeast Caribbean, obtained during different serosurveys performed by our group. Eleven subjects were TSP/HAM patients and 36 were healthy carriers. As negative controls we studied 20 serum samples from HTLV-Iseronegative persons from the same endemic areas. All the persons included in the study 
were informed about the objectives of the investigation and gave their consent for the use of their samples only for research purposes.

ELISA Murex HTLV I + II (Murex Biotech Limited, Dartford, UK) and Serodia PA (Fujirevio, Japan) diagnostic tests were used for seroscreening. The presence of HTLV-I was confirmed using an HTLV blot 2.4 assay (Genelabs ${ }^{\circledR}$ Diagnostics Pte Ltd., Singapore Science Park, Singapore). Additional diagnostic PCR with pol primers was performed on peripheral blood mononuclear cell DNA from all the individuals studied to amplify a 159-bp fragment. All persons included in the study were seronegative for IgG-anti-HIV-1/2 by ELISA (Enzygnost ${ }^{\circledR}$, Behring Dade, Germany) and by Western blot.

\section{Monoclonal antibodies}

Monoclonal antibodies against gag proteins, NOR-1 (anti-p24) (18), GIN-7 (antip19) and WAG-15 (anti-p17) (19); against envelope gp46, LAT-27 (anti-gp46) and against tax, LT-4 (anti-tax-p40) (20) were tested by Western blot with proteins from in vitro cultures of human astrocytes, fetal brains and other non-infected cell cultures from different human tissues.

\section{In vitro cell cultures and tissues}

Primary human astrocytes were obtained by mechanical disaggregation of microdissected sensory motor cortices of human fetuses (embryonic day 116, according to the official Colombian legislation for this material). The dissociated cells were diluted to a density of $2 \times 10^{5}$ cells $/ \mathrm{ml}$ in Dulbecco's modified Eagle's medium (Sigma-Aldrich, St. Louis, MO, USA) containing $25 \mathrm{mM}$ glucose, supplemented with $20 \%$ heat-inactivated fetal calf serum and gentamicin (1 $\mu \mathrm{g} / \mathrm{ml})$. Cells were seeded onto $35-\mathrm{mm}$ diameter culture dishes precoated with poly-
L-lysine $(3 \mu \mathrm{g} / \mathrm{ml}$ in $0.1 \mathrm{M}$ sodium borate buffer, $\mathrm{pH}$ 8.4) (21). Cultures were incubated at $37^{\circ} \mathrm{C}$ in a $5 \%$ moist $\mathrm{CO}_{2}-95 \%$ air atmosphere. Using this procedure, we obtained 3-week-old cultures with more than $99 \%$ of cells with the astrocyte phenotype. Characterization of astrocytes was systematically determined by immunocytochemistry of glial fibrillary acid protein, a specific astrocytic marker, using a polyclonal glial fibrillary acid protein antibody (N-18; Santa Cruz Biotechnology, Santa Cruz, CA, USA).

Human primary lung fibroblasts, skin fibroblasts and kidney cells, cord blood stem cells, HeLa cells, and 3T3 cells were cultured in Eagle's essential medium supplemented with $10 \%$ bovine calf serum and a mix of gentamicin $(1 \mu \mathrm{g} / \mathrm{ml})$, penicillin, streptomycin, and neomycin $(2.5 \mu \mathrm{g} / \mathrm{ml})$ to obtain monolayers with more than $90 \%$ confluence.

Proteins from brain and spinal cord were obtained from non-HTLV-I and HIV-1 postmortem fetuses. Two or $5 \mathrm{~g}$ of tissue was preserved in appropriate transport medium until the time for processing.

\section{Cell lysis}

Approximately $1.0 \times 10^{7}$ cells $/ \mathrm{ml}$ of cultured cells or 2 to $5 \mathrm{~g}$ of tissues were lysed in buffer containing $0.15 \mathrm{M} \mathrm{NaCl}, 0.05 \mathrm{M}$ Tris$\mathrm{HCl}, \mathrm{pH} 7.2,1 \%$ Triton $\mathrm{X}-100,0.1 \%$ sodium dodecyl sulfate (SDS), $1 \%$ sodium deoxycholate, and $2 \mathrm{mM}$ phenylsulfonyl fluoride. Lysates were separated by centrifugation at $14,000 \mathrm{~g}$ for $10 \mathrm{~min}$. Protein concentrations were measured using a protein assay (BioRad, Richmond, CA, USA) as recommended by the manufacturer.

\section{Western blotting}

Proteins from cell cultures and normal tissues were resolved by SDS 8 to $12 \%$ polyacrylamide gel electrophoresis gradient (SDS-PAGE) and passively transferred to 
nitrocellulose membranes (22). The relative molecular masses of proteins were calculated by plotting the logarithm of the relative mobility of the protein $v s$ gel concentration (23).

The membranes were incubated in blocking solution ( $10 \%$ bovine serum albumin in 1X phosphate-buffered saline (PBS), $\mathrm{pH}$ 7.0) overnight at $10^{\circ} \mathrm{C}$. Sera and monoclonal antibodies were diluted $1: 1000$ in $1 \%$ bovine serum albumin, PBS, and $0.2 \%$ Tween-20 and incubated with nitrocellulose strips overnight at $10^{\circ} \mathrm{C}$. Bound autoantibodies were detected by sequential incubation in biotinlabeled anti-human IgG diluted 1:1000, avidin-labeled horseradish peroxidase (Amersham Pharmacia Biotech, Little Chalfont, Buckinghamshire, UK), and $0.05 \%$ diaminobenzidine (Sigma) solution in PBS as described (24).

\section{Immunohistochemistry of rat spinal cord sections}

Young Wistar rats $(250 \mathrm{~g})$ were injected with $40 \mathrm{mg} / \mathrm{kg}$ Ketalar. After total anesthesia

Figure 1. Western blot of proteins obtained from normal human tissues using serum from a TSP/HAM subject. Lane 1, Astrocytes; lane 2, brain; lane 3, lung fibroblasts; lane 4, skin fibroblasts; lane 5, human kidney; lane 6, cord blood stem cells; lane 7, HeLa cells; lane 8, 3T3 cells; lane 9, liver; lane 10, lung, and lane 11, control of reagents. $\mathrm{TSP} / \mathrm{HAM}=$ tropical spastic paraparesis/human T-lymphotropic virus type I (HTLV-I)-associated myelopathy. About $75 \mu \mathrm{g}$ total protein was loaded per line. they were perfused with $150 \mathrm{ml} 0.9 \% \mathrm{NaCl}$ via the ascendant aorta, followed by perfusion of $250 \mathrm{ml}$ buffered formalin, $\mathrm{pH}$ 7.4. The spinal cord was obtained surgically and divided in its anatomical sections, which were post-fixed in buffered formalin, $\mathrm{pH}$ 7.4 , at $4^{\circ} \mathrm{C}$ for $24 \mathrm{~h}$. The tissues were then dehydrated and embedded in paraplast.

Serial sections of spinal cord were cut, deparaffinized and incubated with the LT-4 anti-tax monoclonal antibody (21) using a modification of the original protocol described by Hsu et al. (24). The endogenous peroxidase activity was blocked by incubation with $3 \%$ hydrogen peroxide for $30 \mathrm{~min}$ at room temperature followed by two washes of 5 min each with 0.01X PBS, pH 7.5 (25). Antigen rescue was performed by the method of Shi et al. (26). The serial sections of the spinal cord were incubated overnight with a 1:50 dilution of the anti-tax LT-4 monoclonal antibody. After incubation for $12 \mathrm{~h}$ at $4^{\circ} \mathrm{C}$, slides were washed as described previously and incubated with a secondary antibody (biotinylated goat anti-mouse $\mathrm{IgG}$ ) diluted 1:200 in 1X PBS for $30 \mathrm{~min}$ at room temperature. After this procedure they were washed three times in $1 \mathrm{X}$ PBS and incubated with ABC Elite PK400 (Vector Laboratories, Burlingame, CA, USA) for $30 \mathrm{~min}$, washed again in PBS and immediately developed with diaminobenzidine previously dissolved in Tris- $\mathrm{HCl}$ buffer, $\mathrm{pH} 7.6$, and $0.003 \%$ hydrogen peroxide. Histological preparations were stained with Gill's hematoxylin and mounted permanently in Permount. As negative controls we used human sera from nonHTLV-I- and HIV-1-infected subjects.

\section{Results}

HTLV-I autoantibodies against proteins from central nervous system cells

IgG antibodies against a $98-$ to $100-\mathrm{kDa}$ astrocyte protein were detected in the sera of $100 \%(11 / 11)$ TSP/HAM patients included 
in the study. Moreover, IgG isolated from the same TSP/HAM patients exhibited a specific HTLV-I immunoreactivity with uninfected brain proteins (11/11). Western blots performed with proteins of human non-infected brains showed IgG reactivity with a single $33-$ to $35-\mathrm{kDa}$ protein in all patients. In contrast, no reactive bands with the proteins from primary lung fibroblast, skin fibroblast, human kidney, cord blood stem cells, HeLa, and 3T3 cells were obtained (Figure 1). Sera from asymptomatic healthy HTLV-I carriers and seronegative controls did not exhibit cross-reaction with the 98- to $100-\mathrm{kDa}$ astrocyte or $33-$ to $35-\mathrm{kDa}$ brain proteins.

We included in the study a set of five different HTLV-I monoclonal antibodies. As shown in Figure 2A, a specific cross-reaction of NOR-1 monoclonal antibodies with the 98 - to $100-\mathrm{kDa}$ protein from primary cultured human astrocytes was detected. The $33-$ to $35-\mathrm{kDa}$ brain protein cross-reacted exclusively with the anti-tax LT-4 monoclonal antibody (Figure 2B).

The incubation of different dilutions of NOR-1 with primary human cultured astrocytes revealed that the cross-reaction previously detected was preferentially localized in the cell nucleus. Astrocytes of the spinal cord and primary cultures showed a perinuclear immunostaining that was enhanced by increasing concentrations of the antip24gag monoclonal antibody (Figure 3).

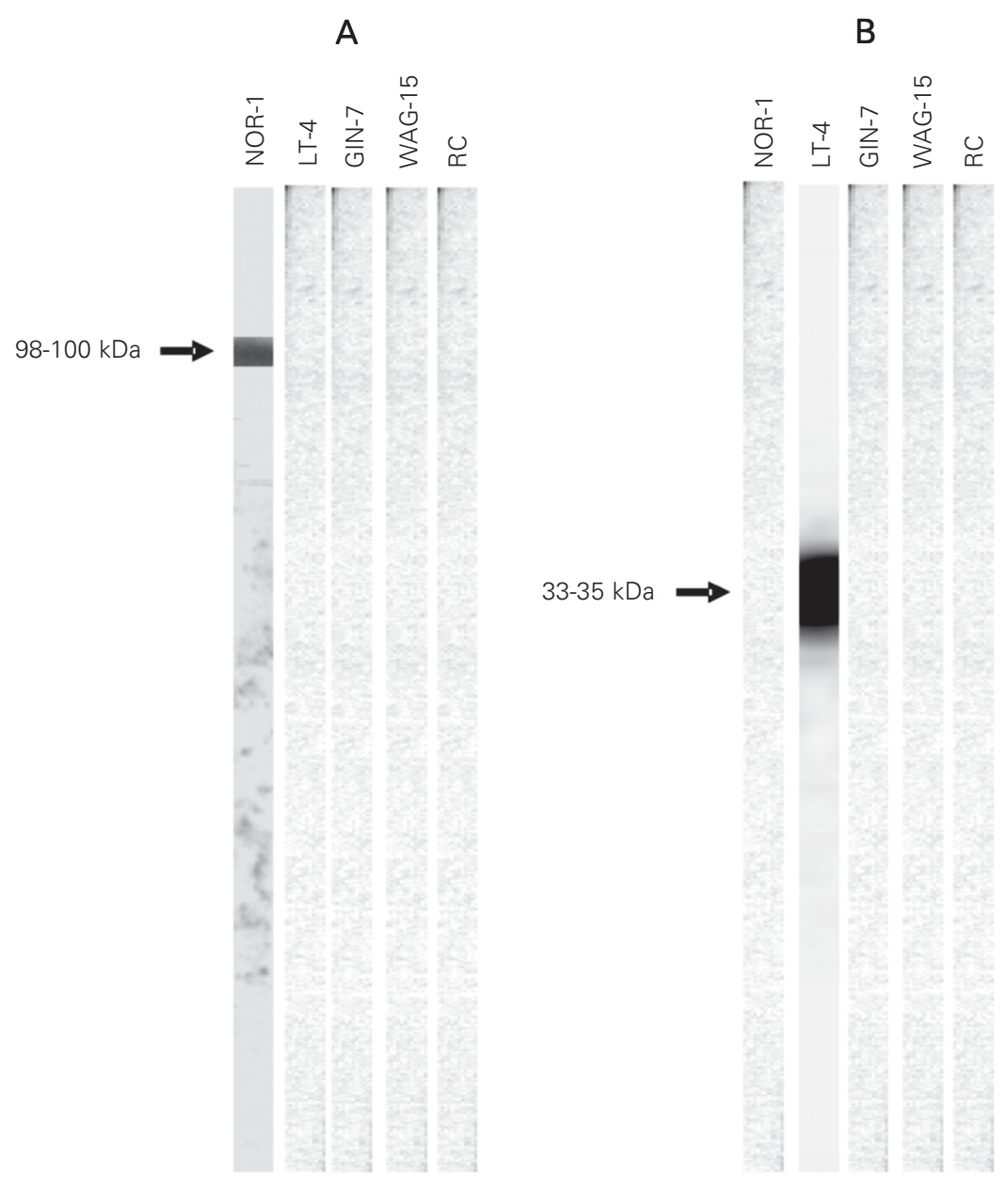

Figure 2. Western blot of proteins obtained from cellular components of the human central nervous system using different monoclonal antibodies (mAb) against human T-lymphotropic virus type I proteins. NOR-1 (mAb for gag p24). LT-4 (mAb for tax p40). GIN-7 (mAb for gag p19). WAG-15 (mAb for gag p17). A, Proteins from primary cultures of human astrocytes. $B$, Proteins from human fetal brain. $R C=$ Reagent control. About $75 \mu \mathrm{g}$ total protein was loaded per line.
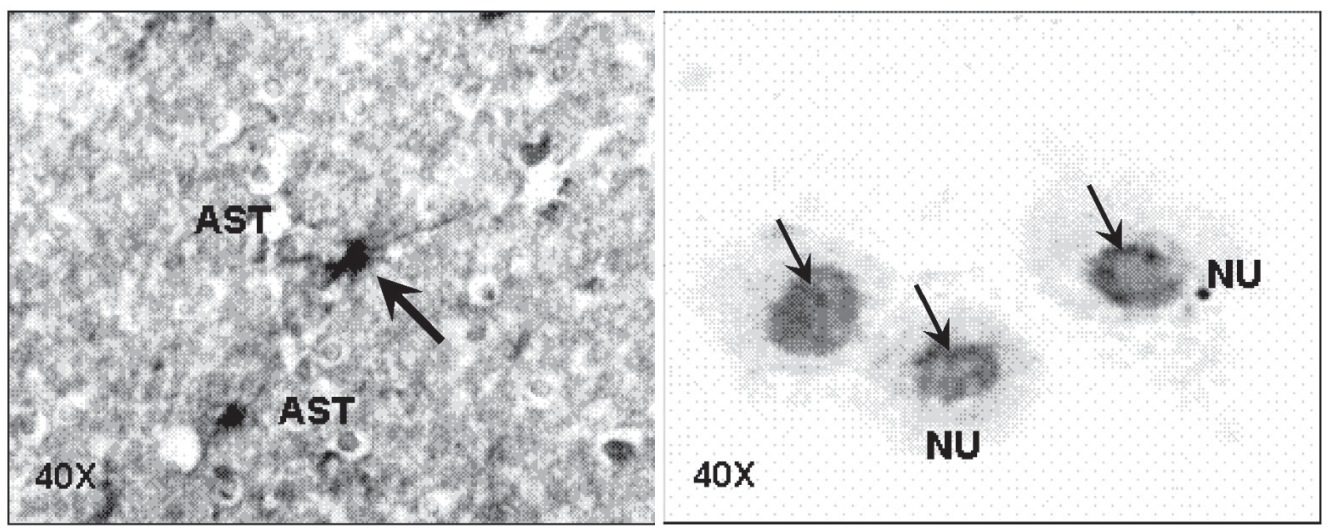

Figure 3. Immunohistochemical reaction of astrocytes with the monoclonal antibody NOR-1 for p24 gag of human T-lymphotropic virus type I. A, Histological preparation of the spinal cord of normal young rat. $B$, Human primary cultures of normal astrocytes. The arrows indicate a positive immunohistochemistry reaction. AST = astrocytes; NU = nuclear cross-reaction. 
Spatial distribution of anti-tax cross-reaction staining in the spinal cord of non-infected rats

In order to assess the location of the antitax LT-4 in cells we studied its cross-reactivity with different areas of thoracic and lumbar spinal cord sections. The immunoreactivity with the monoclonal antibody was predominantly observed as an intense nuclear reaction in clusters of neurons of variable sizes located in different laminae of T6 to L2 sections of spinal cord grey matter (Figure 4A). At the level of the intermediate (lamina VII; Figure 4B) and anterior and posterior (lamina V) horns (medial and lateral IX laminae; Figure 4C), we observed intense crossreaction with the monoclonal LT-4 anti-tax antibody. This situation contrasts with the lack of LT-4 cross-reactivity observed in nerve fibers of white matter, in the ependy-

A

B
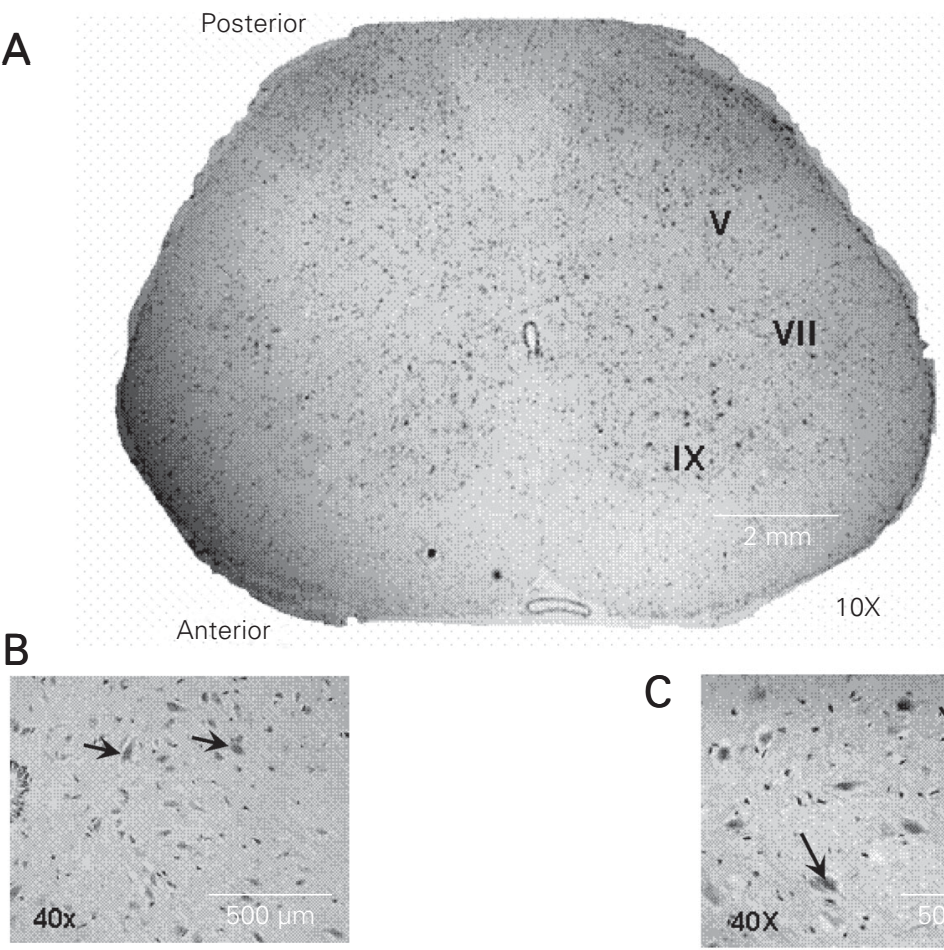

C

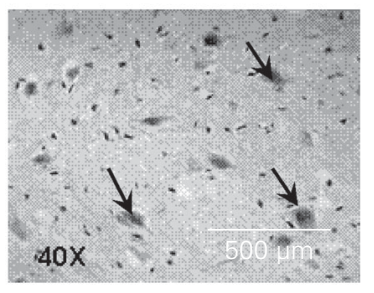

Figure 4. Immunohistochemical reaction of the lumbosacral regions of the spinal cord from a non-human T-lymphotropic virus type l-infected young rat with the monoclonal antibody LT-4 anti-tax. A, General view of motor and sensory areas of the spinal cord that crossreacted (10X). $B$, Nuclear cross-reaction observed in some motor neurons of the spinal cord (lamina VII). C, Motor neurons of lamina IX. The arrows indicate a positive immunohistochemistry reaction. mal channel and in the lamina $X$ (Figure 4A). The negative controls did not exhibit any cross-reaction with the different components of the spinal cord.

\section{Discussion}

An important result of our study was the characterization of the cross-reaction between a perinuclear normal astrocyte protein of 98 to $100 \mathrm{kDa}$ with a monoclonal antibody against HTLV-I p24 (NOR-1). Our results also showed that this mimicry between the two proteins correlates with the presence of anti-98 to 100-kDa autoantibodies in all Colombian TSP/HAM patients tested (11/11). The first report of cross-reaction between sera of TSP/HAM patients and endothelial cells of the brain (23) showed that circulation of these autoantibodies in blood is part of the progression not only of TSP/ HAM but also of other demyelinating disorders. Recent studies have revisited the molecular mimicry with proteins of HTLV-I as a process that may play some role in the progression of TSP/HAM. Although the molecular mimicry between a peptide of the myelin basic protein and a peptide of HTLVI with TSP/HAM was not associated with disease progression (24), there is the possibility that other CNS targets could mimic HTLV-I antibodies. In this respect, our results agree with data showing that IgG isolated from TSP/HAM patients exhibited a specific HTLV-I immunoreactivity with uninfected neurons (13). Neuronal Western blots showed that the IgG reactivity with a single 33- to $35-\mathrm{kDa}$ protein detected in all patients studied is an important process that could play a role in the immunopathogenesis of TSP/HAM (25-27).

Another important result of our study was the characterization of the cross-reaction of a perinuclear normal astrocyte protein of 98-100 $\mathrm{kDa}$ and a nuclear 33- to 35$\mathrm{kDa}$ human brain protein with a monoclonal antibody against HTLV-I p24 (NOR-1) and 
tax-p40 (LT-4), respectively. Our results also showed that autoantibodies against the astrocyte 98 - to $100-\mathrm{kDa}$ and brain 33- to 35$\mathrm{kDa}$ proteins circulate in the Colombian TSP/ HAM patients included in the present study. The first report of cross-reaction between sera from TSP/HAM patients and endothelial cells of the brain (27) showed that circulation of autoantibodies in blood is part of the progression not only of TSP/HAM but also of other demyelinating disorders. In this respect, our results agree with data showing that IgG isolated from TSP/HAM patients exhibits a specific HTLV-I immunoreactivity with uninfected neurons (28-30).

Monoclonal antibodies that bind HIV-1 gp41 and cross-reacted with astrocytes were recovered from the blood of patients infected with HIV-1 (28). Such mimicry by antiviral antibodies interacting with an astrocyte isoform of alpha actinin (29) could play a role in the dementia of AIDS patients. Since HTLV-I-seropositive patients included in the study were indeed seronegative for HIV-1, it is important to consider that the mimicry between astrocyte proteins and viral proteins may be a common feature of the characteristic neural damage observed not only in a neurological disease associated with HIV-1 infection but also in TSP/HAM.

Our results confirmed and extended to human fetal brains and to rat spinal cord the data previously reported by Levin et al. (29) who characterized the molecular mimicry between the HTLV-I tax protein and CNS proteins. In addition to the intense staining of brain neurons, we observed preferential anti-tax IgG staining in the nucleus of $\mathrm{T} 7$ to L2 neurons in the rat spinal cord. These results contrast with the absence of staining of glia and dorsal root ganglia (peripheral nervous system) observed with the tax monoclonal antibody.

Levin et al. (28) have characterized the molecular mimicry between an environmental agent and the CNS. They isolated immunoglobulin $\mathrm{G}(\mathrm{IgG})$ from the serum of pa- tients with TSP/HAM and tested it for reactivity with human tissues. There was intense staining of neurons in the brain and no staining of glia, dorsal root ganglia (peripheral nervous system) or systemic organs. A monoclonal antibody to HTLV-I-tax (tax monoclonal antibody) mimicked IgG staining of neurons. To identify the protein, cortical neurons were isolated and subjected to SDSPAGE and Western blot analysis. The IgG recovered from TSP/HAM patients recognized a band of approximately $33 \mathrm{kDa}$, whereas $\operatorname{IgG}$ isolated from negative controls did not. Importantly, the tax monoclonal antibody that stained CNS neurons reacted with the antigen. Consistent with data reported by Levin et al. (28), our evidence showed that this cross-reaction can be extended to the proteins of fetal human brains because we characterized a similar crossreaction between a 33- to $35-\mathrm{kDa}$ neuronal protein and the monoclonal antibody LT-4 anti-tax.

All patients (13/13) with TSP/HAM that were tested by Levin et al. (28) developed autoantibodies recognizing the neuronal antigen. Nine of ten HTLV-I-seropositive patients without neurological symptoms and 12 HTLV-1-seronegative controls showed no reactivity. All the Colombian TSP/HAM patients studied here reacted against the 33to $35-\mathrm{kDa}$ brain protein, in contrast to none of the HTLV-I-seropositive asymptomatic and HTLV-I-seronegative subjects.

As shown in previous reports, the main pathological feature of TSP/HAM is a chronic inflammation of the spinal cord characterized by perivascular cuffing of mononuclear cells accompanied by parenchymal lymphocyte infiltration (30). Immunological abnormalities arising from a high HTLV-I proviral load in peripheral blood lymphocytes play an important role in the pathological process of spinal cord lesions in TSP/HAM patients (30). Concomitant damage to surrounding CNS tissues, in which CD8+ HTLV-I-specific cytotoxic T lymphocytes attack HTLV- 
I-infected lymphocytes, could be involved in the pathological events of TSP/HAM. In this respect, heightened transmigrating activity of HTLV-I-infected CD4+ T lymphocytes to the CNS tissues may play a key role in the development of TSP/HAM.

The cross-reaction between a 98- to 100$\mathrm{kDa}$ astrocytic protein and the HTLV-I p24 gag protein supports the existence of mimetic targets for viral proteins in this important cell of the CNS. As previously reported, monoclonal antibodies that bound to HIV-1 gp41 and cross-reacted with astrocytes were recovered from the blood of patients infected with HIV-1 (31). Such mimicry by antiviral antibodies interacting with an astrocyte isoform of alpha actinin (32) could play a role in the dementia of AIDS patients. Since the HTLV-I-seropositive patients included in the study were indeed HIV-1 seronegative, it is important to consider that the mimicry between astrocytic proteins and viral proteins may be a common feature of the characteristic neural damage not only in a neurological disease associated with HIV-1 infection but also in TSP/HAM.

Our evidence showed that the molecular mimicry of tax protein is preferentially located in the large neurons of the spinal cord motor areas of T-6 to L-2. As proposed in previous reports, the main pathological feature of TSP/HAM is a chronic inflammation of the spinal cord characterized by perivascular cuffing of mononuclear cells accompanied by parenchymal lymphocyte infiltration. Immunological abnormalities arising from a high HTLV-I proviral load in peripheral blood lymphocytes play an important role in the pathological process of spinal cord lesions in TSP/HAM patients. Although a concomitant damage to the surrounding CNS tissues, in which CD8+ HTLV-I-specific cytotoxic T lymphocytes attack HTLVI-infected lymphocytes, might be involved in the pathological events of the spinal cords of TSP/HAM patients as one of the actual pathogenetic mechanisms, heightened transmigrating activity of HTLV-I-infected CD4+ T lymphocytes to the CNS tissues may play a key role in the development of TSP/HAM.

It is not clear how antibodies could enter the CNS and bind to intracellular antigens located in the neurons of motor spinal cord sections. Previous data indicated that $\mathrm{IgG}$ has a significant role in the pathogenesis of disease. In TSP/HAM, patients are infected with HTLV-I, which is tropic for $\mathrm{CD}^{+}{ }^{+} \mathrm{T}$ lymphocytes. Infection of CD4+ $\mathrm{T}$-lymphocytes results in their activation and may allow them to cross the blood-brain barrier (32). Interaction of these cells with the CNS results in cytokine expression, adhesion molecule and receptor up-regulation, and metalloproteinase secretion. These events are associated with disruption of the bloodbrain barrier. As a consequence, cytotoxic $\mathrm{T}$ lymphocytes and antibodies against tax may enter the CNS. Tax-specific antibodies may home to the neurons and disrupt neuronal function, as suggested by previous studies (12).

The results presented here lead us to conclude that the location of the cross-reaction with the anti-tax LT-4 monoclonal antibody in specific sections of the spinal cord may correlate with the pathological damage mediated by molecular mimicry observed in TSP/HAM. This mimicry may involve axonal degeneration of the motor areas of the spinal cord, mainly those located in the inferior thoracic spinal cord sections. This reasoning opens the possibility to explain the correlation between molecular mimicry and the pathogenesis of TSP/HAM.

\section{Acknowledgments}

We are grateful to Mrs. Angela García and Miss Dilia Franz for editorial assistance. 


\section{References}

1. Fujinami R \& Oldstone MB (1989). Molecular mimicry as a mechanism for virus induced autoimmunity. Immunology Research, 8: 3-15.

2. Fujinami R, Oldstone MB, Wrobleska Z, Frankel ME \& Koprowski $H$ (1983). Molecular mimicry in virus infection: cross-reaction of measles virus phosphoprotein of herpes simplex virus protein with intermediate filaments. Proceedings of the National Academy of Sciences, USA, 80: 2346-2350.

3. Dyrberg T, Peterson JS \& Oldstone MB (1990). Immunological cross-reactivity between mimicking epitopes on a virus protein and human autoantigen depends on a single amino acid residue. Clinical Immunopathology, 54: 290-297.

4. Fujinami RS \& Oldstone MB (1985). Amino acid homology between the encephalitogenic site of myelin basic protein and virus: mechanism for autoimmunity. Science, 230: 1043-1045.

5. Srinivasaapa J, Saegusa J \& Prabhkar B (1986). Molecular mimicry: frequency of reactivity of monoclonal antiviral antibodies with normal tissues. Journal of Virology, 57: 397-401.

6. Casseb J \& Penalva-de-Oliveira AC (2000). The pathogenesis of tropical spastic paraparesis/human T-cell leucemia type I-associated myelopathy. Brazilian Journal of Medical and Biological Research, 33: 1395-1401.

7. Romero IA, Prevost MC, Perret E, Adamson P, Greenwood J, Courad PO \& Ozden S (2000). Interactions between brain endothelial cells and human T-cell leukemia virus type 1-infected lymphocytes: mechanisms of viral entry into the central nervous system. Journal of Virology, 74: 6021-6030.

8. Lehky TJ, Fox CH, Koenig SM, Levin C, Flerlage N, Izumo S, Sato E, Raine CS, Osame M \& Jacobson S (1995). Detection of human Tlymphotropic virus type I (HTLV-I) tax RNA in the central nervous system of HTLV-I-associated myelopathy/tropical spastic paraparesis patients by in situ hybridization. Annals of Neurology, 37: 167175.

9. Kubota R, Umehara F, Izumo S, ljichi S, Matsumuro K, Yashiki S, Fujiyoshi T, Sonoda S \& Osame M (1994). HTLV-I proviral DNA amount correlates with infiltrating CD4+ lymphocytes in the spinal cord from patients with HTLV-I-associated myelopathy. Journal of Neuroimmunology, 53: 23-29.

10. Kira J (1994). The presence of HTLV-I proviral DNA in the central nervous system of patients with HTLV-I-associated myelopathy/ tropical spastic paraparesis. Molecular Neurobiology, 8: 139-145.

11. Froes MM, Correia AH, Garcia-Abreu J, Spray D, Campos AC, Campos de Carvalho AC \& Neto VM (1999). Gap-junctional coupling between neurons and astrocytes in primary central nervous system cultures. Proceedings of the National Academy of Sciences, USA, 96: 7541-7546.

12. Giraudon $P$, Bernard $C$, Malcus N, Dufay $C$, Desgranges M \& Belin F (1995). Retroviral infection (HTLV-I) induces cytokine-regulated immunomodulation and cytotoxicity of medulloblastoma cells. Journal of Neuropathology and Experimental Neurology, 54: 165-174.

13. Giraudon P, Dufay N, Hardin H, Reboul A, Tardy M \& Belin MF (1993). Differentiation of a medulloblastoma cell line towards an astrocytic lineage using the human $T$ lymphotropic retrovirus-1. Neuroscience, 52: 1069-1079.

14. Giraudon $P$, Vernant JC, Confavreux $C$, Belin MF \& Desgranges $C$ (1998). Matrix metalloproteinase 9 (gelatinase B) in cerebrospinal fluid of HTLV-1 infected patients with tropical spastic paraparesis. Neurology, 50: 1920.

15. Moritoyo T, Izumo S, Moritoyo H, Tanaka Y, Kiyomatsu Y, Nagai M,
Usuku K, Sorimachi M \& Osame M (1999). Detection of human Tlymphotropic virus type I p40tax protein in cerebrospinal fluid cells from patients with human T-lymphotropic virus type I-associated myelopathy/tropical spastic paraparesis. Journal of Neurovirology, 5: $241-248$.

16. Umehara F, Okada $Y$, Fujimoto N, Abe M, Izumo S \& Osame M (1998). Expression of matrix metalloproteinases and tissue inhibitors of metalloproteinases in HTLV-l-associated myelopathy. Journal of Neuropathology and Experimental Neurology, 57: 839-849.

17. Chen W, Elias RV, Cao W, Lerious V \& McGinnis JF (1999). Antirecoverin antibodies cause the apoptotic death of mammalian photoreceptor cells in vitro. Journal of Neuroscience Research, 57: 706718.

18. Tanaka $Y$, Lee $B$, Inoi T, Tozawa H, Yamamoto N \& Hinuma $Y$ (1986). Antigens related to three core proteins of HTLV-I (p24, p19 and p15) and their intracellular localizations, as defined by monoclonal antibodies. International Journal of Cancer, 37: 35-42.

19. Tanaka Y, Zeng L, Shiraki H, Shida H \& Tozawa H (1991). Identification of a neutralization epitope on the envelope gp46 antigen of human $T$ cell leukemia virus type I and induction of neutralizing antibody by peptide immunization. Journal of Immunology, 147: 354-360.

20. Lee B, Tanaka $Y$ \& Tozawa $H$ (1989). Monoclonal antibody defining tax protein of human T-cell leukemia virus type-I. Tohoku Journal of Experimental Medicine, 157: 1-11.

21. Yavin E \& Yavin Z (1974). Attachment and culture of dissociated cells from rat embryo cerebral hemispheres on polylysine-coated surface. Journal of Cell Biology, 62: 540-546.

22. Barin F, M'Boup S, Denis F, Kanki P, Allan JS, Lee TH \& Essex M (1985). Serological evidence for virus related to simian T-lymphotropic retrovirus III in residents of West Africa. Lancet, ii: 1387-1389.

23. Nishizawa H, Kita N, Okimura S, Takao E \& Abe Y (1988). Determination of molecular weight of native proteins by polyacrylamide gradient gel electrophoresis. Electrophoresis, 9: 802-806.

24. Hsu S, Raine L \& Fanger H (1981). Use of the avidin-biotin-peroxidase complex $(A B C)$ in immunoperoxidase techniques: a comparison between $A B C$ and unlabeled antibody (PAP) procedures. Journal of Histochemistry and Cytochemistry, 29: 577-580.

25. Hökfelt T, Fuxe K \& Goldstein N (1975). Application of immunochemistry to studies of monoamine cell systems with special reference to nervous tissues. Annals of the New York Academy of Sciences, 254: 407-432.

26. Shi SR, Iman A, Young L, Cote R \& Taylor CR (1995). Antigen retrieval immunohistochemistry under the influenza of $\mathrm{pH}$ using monoclonal antibodies. Journal of Histochemistry and Cytochemistry, 43: 193-201.

27. Tsukada N, Tanaka Y \& Yanagisawa N (1989). Autoantibodies to brain endothelial cells in the sera of patients with human T-lymphotropic virus type I associated myelopathy and other demyelinating disorders. Journal of Neurological Sciences, 90: 33-42.

28. Levin MC, Krichavsky M, Berk J, Foley S, Rosenfeld M, Dalmau J, Chang G, Posner JB \& Jacobson S (1998). Neuronal molecular mimicry in immune-mediated neurologic disease. Annals of Neurology, 44: 87-98.

29. Levin MC, Lee SM, Kalume F, Morcos Y, Dohan Jr FC, Hasty KA, Callaway JC, Zunt J, Desiderio D \& Stuart JM (2002). Autoimmunity due to molecular mimicry as a cause of neurological disease. $\mathrm{Na}$ ture Medicine, 8: 509-513. 
30. Levin MC, Lee SM, Morcos Y, Brady J \& Stuart J (2002). Crossreactivity between immunodominant human $\mathrm{T}$ lymphotropic virus type I tax and neurons: implications for molecular mimicry. Journal of Infectious Diseases, 186: 1514-1517.

31. Eddleston M, de la Torre JC, Xu JY, Dorfman N, Notkins A, ZollaPazner S \& Oldstone MB (1993). Molecular mimicry accompanying
HIV-1 infection: human monoclonal antibodies that bind to gp41 and to astrocytes. AIDS Research and Human Retroviruses, 9: 939-944.

32. Spehar T \& Strand M (1995). Molecular mimicry between HIV-1 gp41 and an astrocyte isoform of alpha actinin. Journal of Neurovirology, 1: 381-390. 